\title{
PROFIL PENGETAHUAN ORANG TUA TERKAIT PENYAKIT CACINGAN DAN PROGRAM DEWORMING SERTA PERILAKU BERISIKO TERKENA CACINGAN PADA ANAK
}

\author{
Ella Yurika, Ade Prima A. S., Nur Fauziah, Arianti Z.C, Naufal Farhan N., Irene Natasia L., Dinda Ayu \\ M., Diona Eldytananda, Fiqi Ervianoer M., Alvina Dewi A., Rufiatid Darojatul F, Gesnita Nugraheni ${ }^{*}$
}

Departemen Farmasi Komunitas, Fakultas Farmasi, Universitas Airlangga Gedung Nanizar Zaman Joenoes Kampus C, Jl. Ir. Soekarno, Surabaya 60115, Indonesia

E-mail: gesnita-n@ff.unair.ac.id

\begin{abstract}
ABSTRAK
Angka cacingan pada anak usia 1-12 tahun di Surabaya masih terhitung banyak walaupun program Pemberian Obat Pencegahan secara Massal (POPM) telah dilaksanakan. Penyakit ini banyak ditemukan di daerah yang padat penduduk dengan warga yang pengetahuannya kurang dalam perilaku hidup bersih dan sehat. Penelitian dilaksanakan untuk mengidentifikasi pengetahuan tentang cacingan dan program POPM serta perilaku berkaitan dengan faktor risiko cacingan. Penelitian ini merupakan cross-sectional study dengan survei menggunakan Interviewer-administered questionnaire pada penduduk yang memiliki anak berusia 1-12 tahun dan menetap di Kecamatan Sawahan, Kota Surabaya lebih dari tiga bulan dengan metode pengambilan data accidental sampling. Hasil survei dari 102 responden menunjukkan bahwa pengetahuan responden masih kurang dalam aspek mengenali gejala cacingan. Data hasil survei menunjukkan bahwa terdapat perilaku berisiko yang dilakukan oleh anak responden seperti tidak menggunakan alas kaki dan bermain di tanah sebanyak $34(33,3 \%)$ dan $31(30,4 \%)$ responden. Hasil Analisis Pearson Correlation menggunakan SPSS versi 22 menunjukkan adanya hubungan positif lemah antara pengetahuan dan perilaku menghindari cacingan $(r=0,199$; signifikansi $=0,044)$. Pengetahuan responden mengenai program deworming atau POPM cukup rendah dengan hanya $34(33,6 \%)$ responden yang mengetahuinya. Peningkatan pengetahuan dan perilaku masyarakat di daerah tersebut diperlukan agar angka infeksi cacingan pada anak dapat berkurang, salah satunya dengan penyuluhan dan pelatihan untuk hidup bersih dan sehat.
\end{abstract}

Kata kunci: Pengetahuan, perilaku, cacingan, kecamatan Sawahan, anak

\begin{abstract}
Although there was already Indonesian deworming program, in 2015, the prevalence of intestinal worm infection at children aged 1-12 years in Surabaya was still 36\%. This infection was high in rural areas with low hygiene education. This study evaluated parents' knowledge regarding intestinal worm infection and deworming program and practice in preventing intestinal worm infection. Cross-sectional study design was performed in this study using interviewer-administered questionnaire. Accidental sampling performed on 102 parents with children aged 1-12 years and stayed in Sawahan district for more than 3 months. This study found that knowledge about symptoms of intestinal worm infection was quite low. There were still risky behaviors on children such as not using footwear and playing on the soil ground in $34(33.3 \%)$ and $31(30.4 \%)$ answers respectively. The Pearson Correlation analysis showed a positive but weak correlation between knowledge and practice in preventing intestinal worm infection $(r=0.199$; significance $=0.044)$. Less than half of respondents $(33.6 \%)$ were familiar with the Indonesian deworming program. There was a need to improve knowledge and practice in the Sawahan district to prevent intestinal worm infection, that could be done in some ways such as education and training for a hygienic and healthy lifestyle.
\end{abstract}

Keywords: Knowledge, practice, intestinal worm infection, Sawahan district, children 


\section{PENDAHULUAN}

Cacingan merupakan penyakit akibat cacing yang menginfeksi tubuh manusia dan ditularkan melalui tanah. Orang yang menderita cacingan dalam pemeriksaan tinjanya mengandung telur cacing dan/atau cacing (Kementerian Kesehatan Republik Indonesia, 2017). Menurut World Health Organization (WHO) pada tahun 2016, lebih dari 1,5 miliar orang di dunia (24\% dari jumlah penduduk dunia) terkena infeksi cacingan. Departemen Kesehatan Republik Indonesia Tahun 2015 menunjukan bahwa prevalensi cacingan pada beberapa provinsi di Indonesia untuk usia 1-12 tahun berada pada tingkat yang tinggi yakni $30 \%-90 \%$, dengan prevalensi di Kota Surabaya sebesar $36 \%$. Pencegahan dan penanggulangan cacingan di Indonesia diatur dalam UndangUndang Nomor 15 tahun 2017 tentang penanggulangan cacingan, salah satu caranya dengan strategi deworming yang dikenal dengan Pemberian Obat Pencegahan secara Massal (POPM). Pada tahun 2015, Kota Surabaya termasuk dalam daerah dengan prevalensi cacingan yang cukup rendah yaitu $<50 \%$, sehingga POPM dilaksanakan minimal sekali dalam setahun. (Kementerian Kesehatan Republik Indonesia, 2017).

Penelitian ini dilakukan di Kelurahan Dukuh Kupang, Kecamatan Sawahan, Surabaya. Sebagian besar daerah tersebut merupakan daerah yang bersih, namun ada satu wilayah pemukiman yang berlokasi dekat dengan tempat pemakaman umum, tempat pembuangan sampah, dan pasar, sehingga potensi terkena cacingan cukup besar. Penelitian yang dilakukan (Shang, 2010) menyatakan sanitasi lingkungan meliputi terdapat tidaknya sumber air bersih dan ketersediaan jamban adalah merupakan faktor yang berperan dalam adanya peningkatan infeksi cacingan yang dapat menular melalui tanah pada siswa Sekolah Dasar di daerah pedesaan. Meningkatnya pengetahuan terkait penyakit cacingan dapat memperbaiki pola hidup masyarakat, sehingga dapat menurunkan angka kejadian penyakit cacingan (Maulana, 2009).

Peran orang tua merupakan faktor penting terhadap perilaku kesehatan anak. Tanpa pengetahuan yang cukup, orang tua tidak dapat menjalankan perannya dalam menjaga perilaku sehat anak secara optimal.

Berdasarkan uraian di atas, pencegahan infeksi penyakit cacingan dapat dilakukan apabila orang tua memiliki pengetahuan terkait penyakit cacingan dan pola hidup bersih. Oleh karena itu, penelitian ini dilakukan untuk mengetahui bagaimana perilaku orang tua di daerah Sawahan, Dukuh Kupang Barat, Surabaya, terkait penyakit cacingan dan strategi deworming untuk mencegah dan membasmi cacingan.

\section{METODE PENELITIAN}

\section{Tempat dan Waktu Penelitian}

Pengambilan data dilakukan di Dukuh Kupang Barat, Kelurahan Dukuh Kupang, Kecamatan Sawahan, Surabaya, Jawa Timur yang kurang lebih dihuni oleh sekitar 400 Kepala Keluarga. Waktu penelitian dilaksanakan pada 13 - 14 September 2019.

\section{Pendekatan dan Jenis Penelitian}

Penelitian ini merupakan studi cross sectional dengan metode survei kepada responden. Sampel diambil secara non-random accidental sampling.

\section{Populasi dan Sampel}

Populasi dalam penelitian ini adalah warga Kelurahan Dukuh Kupang, Kecamatan Sawahan, Surabaya, Jawa Timur. Sampel dalam penelitian ini adalah orang tua dari anak usia prasekolah dan sekolah dasar berumur $1-12$ tahun di daerah Dukuh Kupang Barat. Kriteria inklusi: (1) penduduk yang menetap lebih dari tiga bulan di daerah Dukuh Kupang Barat, (2) memiliki anak usia 1 - 12 tahun.

\section{Teknik Pengumpulan Data}

Teknik pengumpulan data adalah dengan kuesioner yang dibagikan kepada responden secara Interviewer-administered questionnaire yaitu mengisi kuisioner dengan pertanyaan pada kuisioner dibacakan oleh interviewer. Item pertanyaan yang ada pada kuesioner telah melalui validasi isi (content validation) serta validasi rupa (face validation) dengan mengajukan item pertanyaan kepada orang tua dari anak usia $1-12$ tahun dan mengevaluasi adanya pertanyaan yang sulit dipahami atau ambigu. Survei kit terdiri dari lembar penjelasan sebelum penelitian (PSP) yang akan diserahkan kepada responden dan lembar informed consent yang ditandatangani oleh calon responden sebagai bentuk persetujuan calon responden untuk berpartisipasi dalam survei.

\section{Pengukuran variable Pengetahuan}

Pengetahuan diukur dengan 14 item pernyataan, dengan pengkategorian skor pengetahuan dihitung menggunakan skala Guttman yaitu: skor 1 diberikan apabila jawaban benar dan dan skor 0 diberikan apabila 
jawaban salah. Skala ini dipakai bila ingin mendapat jawaban yang tegas terhadap suatu permasalahan yang ditanyakan (Sugiyono, 2012)

Beberapa poin yang akan ditanyakan untuk mengukur variabel pengetahuan adalah (1) Faktor risiko cacingan yaitu (a) buang air besar sembarangan, (b) tidak mencuci tangan dengan sabun, (c) minum air sungai tanpa dimasak, (d) berjalan tanpa alas kaki, (e) memakan kelapa parut, (f) memakan sayuran mentah, (g) buang air besar di tanah, (h) mencuci tangan sebelum makan; (2) gejala cacingan yaitu (a) flu, (b) nafsu makan berkurang; (3) program pemerintah terkait pencegahan infeksi penyakit cacingan yaitu (a) obat cacing diminum sekali seumur hidup, (b) obat cacing diminum sekali setahun.

\section{Perilaku}

Perilaku diukur dari 11 item pertanyaan yang tersusun, untuk menghitung skor kategori perilaku penilainnya yaitu: Skor 4 diberikan untuk pertanyaan positif untuk selalu, 3 untuk sering, 2 untuk kadang - kadang, dan 1 untuk tidak pernah; sedangkan untuk pertanyaan negatif diberi skor 1 untuk selalu, 2 untuk sering, 3 untuk kadang - kadang, dan 4 untuk tidak pernah. Skor total dari semua butir pertanyaan disebut test score yang merupakan hal utama dan menjadi perhatian dalam classical test theory (CTT) (McDonald, 1999; Baker, 2001).

Beberapa poin pertanyaan yang digunakan untuk mengukur variabel perilaku adalah) : (1) Faktor risiko cacingan yaitu (a) mencuci tangan dengan sabun sebelum makan, (b) menggunakan alas kaki saat keluar rumah, (c) buang air besar di jamban, (d) mencuci tangan dengan sabun setelah buang air besar, (e) menggigit kuku, (f) bermain di tanah, (g) mencuci tangan dengan sabun setelah bermain di tanah, (h) makan sayur atau buah yang tidak dimasak; (2) Pencegahan penyakit cacingan yaitu (a) mengonsumsi obat cacing.

\section{Analisa Data}

Variabel pengetahuan dan perilaku dianalisis secara deskriptif dengan menyajikan frekuensi (n) dan persentase (\%). Data disajikan dalam tabel dan diagram. Analisis hubungan pengetahuan dan perilaku terkait infeksi penyakit cacingan secara kuantitatif dilakukan dengan program komputer IBM Statistical Package for the Social Science (SPSS) 21 versi 15.0. Data dikatakan signifikan jika nilai $\mathrm{p}<$ 0,05 .

\section{HASIL DAN PEMBAHASAN}

\section{Karakteristik Sosiodemografik}

Karakteristik sosiodemografik responden dapat dilihat pada tabel 1. Jumlah responden pada penelitian ini sebanyak 102 orang tua. Responden penelitian sebagian besar adalah perempuan dengan jumlah 98 responden $(96,1 \%)$, sejumlah 43 responden berada pada rentang usia 29-38 tahun, sejumlah 38 responden berpendidikan terakhir SD, rentang penghasilan 500.000-1.500.000 sebanyak 34 responden $(33.3 \%)$, dan mempunyai anak 1-3 orang sebanyak 76 responden $(74,51 \%)$. Gender perempuan paling banyak diperoleh karena pengambilan data dilakukan siang sampai sore hari, pada saat itu banyak dijumpai ibu-ibu yang sedang berkumpul di luar rumah. Wilayah yang digunakan sebagai lokasi pengambilan data berada di kawasan menengah ke bawah.

\section{Response Rate}

Dari 146 orang yang ditawarkan untuk terlibat dalam penelitian, terdapat 36 orang yang menolak untuk mengisi kuesioner. Total responden yang menolak sebesar $33 \%$, sehingga Response Rate (RR) yang didapat sebesar $67 \%$. Hal ini menunjukkan respon dari masyarakat daerah Kelurahan Dukuh Kupang, Kecamatan Sawahan untuk mengisi kuesioner cukup baik.

Tabel 1. Karakteristik Sosiodemografi Responden (N $=102$ responden

\begin{tabular}{lc}
\hline \multicolumn{1}{c}{ Variabel } & $\mathrm{r}(\%)$ \\
\hline Usia & \\
18-28 Tahun & $21(20,59 \%)$ \\
29-38 Tahun & $43(42,15 \%)$ \\
39-48 Tahun & $28(27,45 \%)$ \\
49-58 Tahun & $10(9,80 \%)$ \\
\hline Jenis kelamin & \\
Perempuan & $98(96,1 \%)$ \\
Laki-laki & $4(3,9 \%)$ \\
\hline Tingkat Pendidikan & \\
Tidak sekolah & $12(11,8 \%)$ \\
SD & $38(37,3 \%)$ \\
SMP & $19(18,6 \%)$ \\
SMA/SMK & $31(30,4 \%)$ \\
S1 & $2(2,0 \%)$ \\
\hline Penghasilan & \\
$<500000$ & $27(26,5 \%)$ \\
$500000-1500000$ & $34(33,3 \%)$ \\
1500000-2500000 & $25(24,5 \%)$ \\
$2500000-3800000$ & $13(12,7 \%)$ \\
$3800000-5000000$ & $1(1 \%)$ \\
$>5000000$ & $2(2 \%)$ \\
\hline Jumlah anak & \\
$1-3$ & $76(74,51 \%)$ \\
$4-5$ & $23(22,55 \%)$ \\
$6-8$ & $3(2,94 \%)$ \\
\hline \hline
\end{tabular}


Dari 110 responden yang bersedia mengisi kuesioner, terdapat 8 data yang dieksklusi karena memiliki potensi bias dimana responden menjawab tidak tahu pada pertanyaan pengetahuan pertama yaitu "apakah anda pernah mendengar mengenai penyakit cacingan" namun dapat menjawab pertanyaan pengetahuan lainnya. Potensi bias kemungkinan terjadi karena awalnya responden telah menjawab tidak tahu namun ternyata memiliki pengetahuan mengenai penyakit cacingan.

\section{Pengetahuan tentang Cacingan}

Hasil penelitian survei menunjukkan sebanyak $41(40,2 \%)$ responden menjawab benar dan $61(59,8 \%)$ responden menjawab salah pada pernyataan pengetahuan bahwa flu merupakan salah satu gejala penyakit cacingan. Hal ini menandakan bahwa masih banyak masyarakat yang tidak mengetahui bahwa flu bukan merupakan salah satu gejala penyakit cacingan. Sebanyak $72(70,6 \%)$ responden menjawab benar dan $30(29,4 \%)$ menjawab salah pada pernyataan nomor 8 bahwa nafsu makan berkurang merupakan gejala cacingan, dapat dilihat pada Tabel 2. Dari data tersebut dapat dilihat bahwa sudah banyak masyarakat yang mengetahui gejala penyakit cacingan yaitu nafsu makan berkurang akibat adanya cacing dewasa yang hidup didalam mukosa usus. Menurut CDC, gejala penyakit cacingan yang sering dialami anak-anak yang terinfeksi oleh cacing, yaitu perut terlihat buncit, timbulnya rasa sakit pada perut, mengalami diare, dan penurunan nafsu makan (Centers for Disease Control and Prevention, 2009). Nyeri perut dengan kolik di daerah pusat atau epigastrium, perut buncit (pot belly), anoreksia, susah tidur, dan diare merupakan gejala penyakit cacingan (Amelasari et al., 2015).

Tabel 2. Profil Pengetahuan Masyarakat terkait Penyakit Cacingan

\begin{tabular}{rlcc}
\hline \hline \multirow{2}{*}{ No } & \multicolumn{1}{c}{ Pertanyaan } & \multicolumn{2}{c}{ Jawaban (\%) } \\
\cline { 3 - 4 } & \multicolumn{1}{c}{ Benar } & Salah \\
\hline 1 & Buang air besar sembarangan dapat menyebabkan cacingan & 75,5 & 24,5 \\
\hline 2 & $\begin{array}{l}\text { Tidak mencuci tangan menggunakan sabun setelah buang } \\
\text { air besar dapat menyebabkan penyakit cacingan }\end{array}$ & 92,2 & 7,8 \\
\hline 3 & Flu merupakan salah satu gejala penyakit cacingan & 40,2 & 59,8 \\
\hline 4 & $\begin{array}{l}\text { Minum air sungai tanpa dimasak tidak menyebabkan } \\
\text { cacingan }\end{array}$ & 53,9 & 46,1 \\
\hline 5 & Berjalan tanpa alas kaki bisa berisiko cacingan & 58,8 & 41,2 \\
\hline 6 & Memakan kelapa parut menyebabkan cacingan & 15,7 & 84,3 \\
\hline 7 & $\begin{array}{l}\text { Memakan sayur mentah tanpa dicuci menyebabkan } \\
\text { cacingan }\end{array}$ & 68,6 & 31,4 \\
\hline 8 & Nafsu makan berkurang merupakan gejala cacingan & 70,6 & 29,4 \\
\hline 9 & Buang air besar di tanah tidak menyebabkan cacingan & 46,1 & 53,9 \\
\hline 10 & Mencuci tangan sebelum makan bisa mencegah cacingan & 86,3 & 13,7 \\
\hline 11 & Obat cacing hanya diminum sekali seumur hidup & 78,4 & 21,6 \\
\hline 12 & Obat cacing diminum minimal sekali setahun & 63,7 & 36,3 \\
\hline \hline
\end{tabular}

Faktor risiko yang menyebabkan penyakit cacingan yaitu sanitasi lingkungan yang buruk, tidak mencuci tangan dengan sabun sebelum makan, Buang Air Besar (BAB) sembarangan dan memakan sayuran mentah tanpa dicuci (Fitri et al., 2012). Hasil penelitian survei menunjukkan lebih dari 50\%, yaitu 77 responden $(75,59 \%)$ sudah menjawab benar mengenai faktor resiko seperti Buang Air Besar (BAB) sembarangan dapat menyebabkan penyakit cacingan. Perilaku BAB sembarangan dapat menyebabkan tanah dan lingkungan tercemar oleh feses, dimana feses mengandung telur cacing dan dapat menyebabkan terjadinya infeksi cacingan. Terdapat $94 \quad(92,2 \%)$ responden yang menjawab benar pada pernyataan tidak mencuci tangan menggunakan sabun setelah BAB dapat menyebabkan cacingan. Sebanyak $88 \quad(86,3 \%)$ responden menjawab benar pada pernyataan mencuci tangan sebelum makan bisa mencegah penyakit cacingan. Kontak dengan tanah yang terkontaminasi oleh telur cacing tanpa disertai dengan perilaku mencuci tangan sebelum makan, setelah BAB, dan bemain diluar rumah sering menjadi cara penularan penyakit cacingan (WHO, 2019).

Faktor risiko lain seperti minum air sungai tanpa dimasak juga dipahami oleh $55(53,9 \%)$ responden dan tidak menggunakan alas kaki saat keluar rumah merupakan risiko cacingan dijawab oleh $60(58,8 \%)$ responden. Hal ini serupa dengan penelitian Jalaluddin yang menunjukkan terdapat hubungan antara infeksi cacingan dan pemakaian alas kaki (Jalaluddin, 2009). Selain itu penelitian yang dilakukan oleh Siti kamariah pada anak SDIT Wihdatul Umamah di Makasar menunjukkan bahwa 
penggunaan alas kaki adalah salah satu faktor risiko dalam kejadian kecacingan (Kamariah, 2014).

Sebanyak $70(68,6 \%)$ responden menjawab benar pada pernyataan memakan sayuran mentah tanpa dicuci menyebabkan cacingan. Penelitian Jalaluddin pada tahun 2009 menunjukkan ada hubungan sanitasi lingkungan rumah terhadap terjadinya infeksi cacingan. Keadaan lingkungan yang tidak sehat dapat menjadi faktor risiko penyakit cacingan, sehingga dapat meningkatkan kasus infeksi cacingan (Jalaluddin, 2009). Hal tersebut sesuai dengan teori Blum yang menyatakan bahwa kesehatan individu maupun masyarakat dipengaruhi oleh faktor lingkungan (Blum, 1974).

Sebanyak $86(84,3 \%)$ responden menjawab salah pada pernyataan memakan kelapa parut menyebabkan penyakit cacingan. Hal ini dapat disebabkan karena kelapa parut merupakan salah satu mitos penyebab terjadinya infeksi cacingan. Sedangkan penularan infeksi cacingan utamanya disebabkan oleh kebersihan makanan bukan disebabkan oleh jenis bahan makanan (Surya dan Sungkar, 2013).

Berdasarkan hasil survei, pengetahuan masyarakat di Kelurahan Dukuh Kupang di Kecamatan Sawahan masih cukup rendah dalam beberapa aspek, terutama pada pernyataan pengetahuan nomor 3 , nomor 6 , dan nomor 8 . Jika sudah terinfeksi, penanggulangan cacing beserta telurnya dimulai dari membunuh cacing dengan pemberian obat untuk menekan terjadinya infeksi, sehingga dapat memperbaiki derajat kesehatan penderita. Selain itu, perlu upaya pencegahan dengan menjaga kebersihan diri sendiri maupun lingkungan secara konsisten, karena pemberian obat-obatan hanya bersifat mengobati tetapi tidak memutuskan rantai penularan infeksi cacingan (Kementerian Kesehatan Republik Indonesia, 2017).

Pemerintah telah melakukan upaya melalui Dinas Kesehatan untuk mengatasi masalah tersebut dengan pemberian obat cacing gratis dan penyuluhan kesehatan oleh tenaga kesehatan seperti dokter, apoteker, dan bidan atau Dinas Kesehatan Daerah melalui posyandu atau puskesmas. Apabila masyarakat menunjukkan respon yang pasif terhadap program tersebut, petugas dapat langsung mendatangi masyarakat ke rumah-rumah, upaya lainnya dengan perbaikan sanitasi lingkungan, peningkatan status gizi, kebersihan perorangan serta partisipasi masyarakat (Departemen Kesehatan Republik Indonesia, 2015).

\section{Pengetahuan tentang Program Deworming}

Pengetahuan masyarakat Kelurahan Dukuh Kupang di Kecamatan Sawahan mengenai program pemerintah tentang pembasmian penyakit cacingan (deworming) atau Pemberian Obat Pencegahan secara Masal (POPM) dapat dilihat cukup rendah. Hanya 34 responden $(33,6 \%)$ dari 102 responden yang mengetahui dan dapat menjawab tentang program pemerintah tersebut. Program pemerintah yang telah diketahui oleh masyarakat diantaranya adalah pemberian obat pencegah penyakit cacingan di Puskesmas dan di Sekolah Dasar oleh tenaga kesehatan. Selain itu, sebanyak 68 responden lainnya $(66,4 \%)$ menjawab tidak mengetahui atau pernah mendengar, namun tidak tahu apa program pemerintah tersebut. Sebagian dari responden yang mengaku tidak mengetahui tentang POPM dapat menyebutkan salah satu contoh POPM setelah diberikan penjelasan oleh surveyor.

Pemerintah memiliki program pemberian obat cacing yang dilakukan secara serentak kepada semua penduduk sasaran di wilayah beresiko cacingan yang disebut dengan POPM. POPM diadakan di daerah dengan prevalensi cacingan tinggi selama dua kali dalam satu tahun dan untuk daerah dengan prevalensi cacingan sedang diberikan selama satu kali dalam satu tahun. Obat yang diberikan saat program POPM yaitu Albendazol dan Mebendazol (Kementerian Kesehatan Republik Indonesia, 2017). Banyak responden yang tidak mengetahui mengenai program POPM. Hal itu disebabkan karena penyebaran informasi tentang POPM masih kurang sehingga masyarakat masih belum mengetahui adanya program tersebut. Selain itu, kemungkinan masyarakat daerah tersebut memang tidak memiliki keinginan untuk mencari tahu mengenai program dari pemerintah untuk mencegah penyakit cacingan pada anak-anak. Masyarakat yang mengetahui program pemerintah tersebut mayoritas mendapat informasi dari posyandu dan puskesmas. Data survei ini dapat dijadikan saran untuk pemerintah agar pemerintah lebih menggencarkan penyuluhan dan pemberian informasi tentang POPM melalui fasilitas pelayanan kesehatan.

\section{Perilaku tentang Penyakit Cacingan}

Data lengkap mengenai profil perilaku responden terkait risiko cacingan dapat dilihat pada Tabel 3. Variabel yang diukur adalah faktor risiko cacingan yang diwakili oleh pertanyaan nomor 1,2,3,4,5,6,7,8 dan pengobatan cacingan yang diwakili pertanyaan 
nomor 9. Perilaku responden tentang mencuci tangan sebelum makan dengan sabun, BAB di jamban atau WC, mencuci tangan setelah $\mathrm{BAB}$, dan tidak mengkonsumsi makanan mentah sudah baik dan diterapkan sehari-hari, hal ini sesuai dengan hasil pengetahuan yang menunjukkan jawaban benar yang tinggi. Akan tetapi, pengetahuan yang baik belum tentu dilaksanakan oleh responden. Pengetahun masyarakat tentang penggunaan obat cacing sudah baik namun belum diimbangi dengan perilaku yang benar, dapat dilihat dari persentase jawaban responden yang anaknya tidak pernah minum obat cacing masih relatif tinggi $(25,5 \%)$ sehingga perlu upaya pencegahan dari pemerintah dengan lebih mensosialisasikan pengobatan massal cacingan. Sebanyak 33,3\% jawaban responden menyatakan bahwa anak mereka sesekali tidak memakai sandal saat keluar rumah. Hal ini tidak sesuai dengan hasil pengetahuan yang menunjukkan persentase benar lebih dari $50 \%$. Maka dari itu, perlu dibiasakan untuk menggunakan alas kaki sebagai upaya pencegahan (preventive) agar meminimalkan risiko cacingan. Sama halnya dengan perilaku bermain di tanah juga masih banyak dilakukan oleh anak dari responden. Perilaku tersebut menunjukkan bahwa anak masih berpotensi terpapar risiko cacingan, sehingga perlu dilakukan upaya preventif salah satunya dengan mencuci tangan dengan sabun setelah bermain dengan gerakan 6 dasar dan selalu menggunakan alas kaki saat keluar rumah.

Pemerintah telah menggalakkan kampanye Hari Cuci Tangan Pakai Sabun Sedunia (HCTPS) sebagai upaya untuk menurunkan tingkat kematian balita dan pencegahan terhadap penyakit yang dapat berdampak pada penurunan kualitas hidup manusia. Kampanye ini adalah sebuah gerakan yang bersifat global. Penyakit-penyakit yang dapat dicegah melalui program tersebut meliputi infeksi saluran pernafasan, pneumonia, diare, infeksi cacing, infeksi mata, dan penyakit kulit (Kementerian Kesehatan Republik Indonesia, 2014).

\section{Analisa Korelasi antara Pengetahuan dan Perilaku}

Metode yang digunakan dalam menganalisa hubungan antara pengetahuan dan perilaku untuk menghindari penyakit cacingan ditentukan dari analisa normalitas data menggunakan metode Kolmogorov-Smirnov test dan diperoleh nilai Asymp. Sig (2-tailed) = 0,376 sehingga dapat disimpulkan bahwa data berdistribusi normal. Hasil analisa hubungan antara pengetahuan dan perilaku untuk menghindari cacingan menggunakan analisis Pearson Correlation diperoleh nilai $p=0,044$ dan $r=0,199$. Nilai $p$ menunjukkan adanya hubungan antar pengetahuan dan perilaku untuk menghindari cacingan dan nilai $r$ menunjukkan adanya hubungan positif lemah antara pengetahuan dan perilaku untuk menghindari penyakit cacingan. Semakin baik pengetahuan, maka perilaku untuk menghindari penyakit cacingan semakin baik. Hasil ini sejalan dengan penelitian yang dilakukan oleh (Bieri et al., 2013) mengenai program edukasi kesehatan untuk mencegah infeksi cacingan. Efektivitas yang diperoleh yaitu sebesar 50\% dapat mencegah penyakit cacingan pada anak usia sekolah di China. Penurunan angka infeksi ini berhubungan dengan meningkatnya pengetahuan sehingga memperbaiki perilaku menjaga kebersihan. Penelitian membuktikan bahwa prinsip intervensi dengan edukasi kesehatan meningkatkan pengetahuan siswa tentang penyakit cacingan dan mengubah perilaku yang dapat menurunkan risiko infeksi. Intervensi dengan metode ceramah lebih baik dibandingkan metode tertulis karena dapat meningkatkan pengetahuan masyarakat secara lebih bermakna (Pasaribu, 2005).

Untuk mencegah adanya infeksi yang berulang, dilakukan dengan mendisiplinkan perilaku hidup bersih dan sehat antara lain tidak melakukan kontak dengan tanah, mencuci buahbuahan dengan air bersih sebelum dimakan, mencuci tangan dengan sabun setelah menggunakan toilet, defekasi dan buang air di toilet, menjaga kebersihan kuku dan tetap pendek, dan mimum dengan air yang bersih. Oleh karena itu, faktor penting untuk memperbaiki kesehatan berasal dari faktor perilaku. Adanya peningkatan pengetahuan dapat memperbaiki perilaku dan dapat meningkatkan derajat kesehatan, sehingga dapat mengurangi tingginya kejadian akan penyakit tersebut

(Maulana, 
Tabel 3. Profil Perilaku Responden Terkait Risiko

\begin{tabular}{lllll}
\multicolumn{1}{c}{ Item } & \multicolumn{1}{c}{ Selalu } & Sering & $\begin{array}{c}\text { Kadang- } \\
\text { Kadang }\end{array}$ & $\begin{array}{c}\text { Tidak } \\
\text { Pernah }\end{array}$ \\
\hline $\begin{array}{l}\text { Apakah anak Anda setiap mau makan mencuci tangan } \\
\text { dengan sabun? }\end{array}$ & $65(63,7 \%)$ & $18(17,6 \%)$ & $17(16,7 \%)$ & $2(2,0 \%)$ \\
\hline $\begin{array}{l}\text { Apakah anak Anda menggunakan alas kaki saat keluar } \\
\text { rumah? }\end{array}$ & $54(52,9 \%)$ & $12(11,8 \%)$ & $34(33,3 \%)$ & $6(5,9 \%)$ \\
\hline Apakah anak Anda buang air besar di jamban/ WC? & $88(86,3 \%)$ & $3(2,9 \%)$ & $5(4,9 \%)$ & $6(5,9 \%)$ \\
\hline $\begin{array}{l}\text { Apakah anak Anda setelah buang air besar mencuci } \\
\text { tangan dengan sabun? }\end{array}$ & $93(91,2 \%)$ & $4(3,9 \%)$ & $3(2,9 \%)$ & $2(2,0 \%)$ \\
\hline Apakah anak Anda kebiasaan mengigit kuku? & $5(4,9 \%)$ & $7(6,9 \%)$ & $28(27,5 \%)$ & $62(60,8 \%)$ \\
\hline Apakah anak Anda kebiasaan bermain di tanah? & $19(18,6 \%)$ & $18(17,6 \%)$ & $31(30,4 \%)$ & $34(33,3 \%)$ \\
\hline $\begin{array}{l}\text { Apakah anak Anda mencuci tangan dengan sabun setelah } \\
\text { bermain di tanah? }\end{array}$ & $69(67,6 \%)$ & $7(6,9 \%)$ & $7(6,9 \%)$ & $19(18,6 \%)$ \\
\hline $\begin{array}{l}\text { Apakah anak Anda makan makanan mentah misalnya } \\
\text { sayur, buah yang tidak dimasak? }\end{array}$ & $3(2,9 \%)$ & $4(3,9 \%)$ & $10(9,8 \%)$ & $85(83,3 \%)$ \\
\hline Apakah Anda pernah mengonsumsi obat cacingan? & $49(48,0)$ & $18(17,6 \%)$ & $9(8,8 \%)$ & $26(25,5 \%)$ \\
\hline \hline
\end{tabular}

\section{KESIMPULAN}

Dari hasil penelitian dapat dilihat bahwa tingkat pendidikan masyarakat di Kelurahan Dukuh Kupang, Kecamatan Sawahan tentang penyakit cacingan sudah cukup baik namun terdapat beberapa mitos dan kebiasaan warga yang tidak diketahui ternyata dapat meningkatkan risiko terinfeksi penyakit cacingan. Perilaku masyarakat disana juga masih ada yang menjadi faktor risiko untuk terinfeksi penyakit cacing yaitu berjalan tanpa alas kaki di tanah yang kotor, namun untuk perilaku lainnya masyarakat sudah cukup baik dalam menerapkan gaya hidup yang bersih walaupun hidup di daerah yang padat dan kotor. Untuk meningkatkan pengetahuan dan perilaku masyarakat di daerah ini perlu adanya intervensi berupa penyuluhan dan pelatihan kepada masyarakat untuk dapat menerapkan hidup bersih dan sehat agar tidak terkena penyakit cacingan.

\section{UCAPAN TERIMAKASIH}

Terima kasih kami ucapkan kepada Tuhan Yang Maha Esa, Dekan Fakultas Farmasi Universitas Airlangga, Ibu Gesnita Nugraheni, S.Farm., MS., Apt. selaku dosen pembimbing kelompok, dosen-dosen pengajar mata kuliah Farmasi Masyarakat, warga kelurahan dukuh kupang, serta semua pihak yang telah banyak membantu dilaksanakannya survei ini.

\section{DAFTAR PUSTAKA}

Amelasari, O., Hidayah, N., \& Ain, H. 2015. Pengetahuan orang tua tentang infeksi kecacingan pada anak usia sekolah dasar.
Pendidikan Kesehatan, Vol.4, No.2, p.91-98.

Baker, B.2001. 'The Basics of Item Response Theory'. ERIC Clearinghouse on Assessment and Evaluation.

Bieri, F. A., Gray, D. J., Williams, G. M., Raso, G., Li, Y.-S., Yuan, L., Donald P. McManus, D. S.2013. Health-Education Package to Prevent Worm Infections in Chinese Schoolchildren. p.1603-1612.

Blum, H. L.1974. Planning for Health: Development and Application of Social Change Theory. New York: Behavioral Publications.

Centers for Disease Control and Prevention.2009. Soil Transmitted Helminths (STH).

Departemen Kesehatan Republik Indonesia. 2015. Profil Kesehatan Indonesia 2015. Jakarta: Departemen Kesehatan Republik Indonesia.

Fitri, J., Saam, Z. and Hamidy, M. Y.2012. Murid sekolah dasar di kecamatan angkola timur kabupaten tapanuli selatan tahun 2012. pp. 146-161.

Jalaluddin.2009. Pengaruh sanitasi lingkungan, personal hygiene dan karakteristik anak terhadap infeksi kecacingan pada murid sekolah dasar di kecamatan blang mangat kota lhokseumaw.

Kamariah, S.2014. Hubungan Sanitasi Lingkungan Dan Pola Asuh Dalam Perspektif Islam Terhadap Kejadian Kecacingan Pada Anak Sekolah Dasar Islam Terpadu (Sdit) Wihdatul Ummah Kota Makassar. Skripsi: Makasar. UIN Alauddin.

Kementerian Kesehatan Republik Indonesia.2014. Perilaku Cuci Tangan Pakai Sabun di Indonesia.

Kementerian Kesehatan Republik Indonesia.2017. Peraturan menteri kesehatan republik indonesia nomor 15 tahun 2017 
tentang penanggulangan cacingan.

Maulana HDJ. 2009. Promosi Kesehatan. Jakarta: EGC. p. 7-8.

McDonald, R. P. 1999. Test theory: A unified treatment. Mahwah, NJ: Lawrence Erlbaum Associates.

Notoadmojo, Soekidjo. 2003. Pendidikan Dan Perilaku Kesehatan. Rineka Cipta. Jakarta

Pasaribu. 2005. Perbandingan Penyuluhan Kesehatan Metode Ceramah Tanya Jawab Dengan Penyuluhan Kesehatan Menggunakan Buku Kecacingan Dalam Mencegah Reinfeksi Ascaris lumbricoides Pada Anak Sekolah Dasar, (http://eprints.undip.ac.id/17659/ 1/Hotber_ER_ Pasaribu.pdf) diakses 27 September 2019.

Shang Y, Tang L, Zhou S, Chen Y, Yang Y, Lin S. 2010. Stunting and Soil transmitted helminth Infections among School-age Pupils in Rural Areas of Southern China. Journal Parasites \& Vectors, Vol.3:97.

Sugiyono. 2013. Metode Penelitian Pendidikan Pendekatan Kuantitatif, Kualitatif, dan R\&D. Bandung: Alfabeta

Surya, D. and Sungkar, S. 2013. Efektivitas Penyuluhan terhadap Tingkat Pengetahuan Guru SD di Jakarta Mengenai Pencegahan Cacingan, Tahun 2011. Vol. 1 No.3, pp. 195201.

WHO. 2016. WHO guidelines on hand hygiene in health care'.

WHO. 2019. Soil Transmitted Helminth infections'.

https://www.who.int/newsroom/factsheets/det ail/soil-transmitted-helminth-infections.

Diakses pada 22 November 2019. 